\title{
GAMBARAN KEBIASAAN MEROKOK PENDUDUK DI INDONESIA
}

\begin{tabular}{|c|}
\hline Dodi Satriawan \\
Badan Pusat Statistik Kab. Padang Lawas Utara \\
dodisatriawan@bps.go.id
\end{tabular}

Diterima: Januari 2021; Disetujui: April 2021

\begin{abstract}
Smoking is a habit can damage health and can cause various diseases can lead to morbidity and mortality where the Crude Mortality Rate $(C D R)$ is one of the mortality parameters. The purpose of this study was to determine the description the Crude Mortality Rate in Indonesia as well as the description of the population smoking in Indonesia according to gender, activity in the last week, health complaints and smoking habits in the last month and before the last month. The data used in this research is SUSENAS March 2019 data and the analysis used is descriptive analysis. From the research results, it can be seen that Indonesia's CDR decline is faster than the world. From the results of 2019 SUSENAS data, it is known the majority of smoking habits are carried out by men and only a small proportion of women, only a small proportion of active smokers experience health complaints but there is a tendency to increase the percentage of health complaints for residents who have smoking habits are practiced everytime. Before the last month (SUSENAS) and the number of active smokers who smoke every day from among the population who are taking care of the household.
\end{abstract}

Keyword: mortality, smoking habits, susenas.

Abstraksi. Merokok merupakan kebiasaan yang dapat merusak kesehatan dan dapat menyebabkan berbagai macam penyakit yang dapat berakibat kepada terjadinya morbiditas maupun mortalitas dimana Angka Kematian Kasar (CDR) merupakan salah satu parameter mortalitas. Tujuan dari penelitian ini adalah untuk mengetahui gambaran Angka Kematian Kasar di Indonesia serta gambaran penduduk yang merokok di Indonesia menurut jenis kelamin, kegiatan seminggu terakhir, keluhan kesehatan dan kebiasaan merokok satu bulan terakhir dan sebelum satu bulan terakhir. Data yang digunakan dalam penelitian ini adalah data SUSENAS Maret 2019 dan analisis yang digunakan adalah analisis deskriptif. Dari hasil penelitian dapat dilihat bahwa penurunan CDR Indonesia lebih cepat dibandingkan Dunia. Dari hasil olah data SUSENAS tahun 2019 diketahui bahwa mayoritas kebiasaan merokok dilakukan oleh laki-laki dan hanya sebagian kecil perempuan, hanya sebagian kecil saja dari perokok aktif yang mengalami keluhan kesehatan namun terjadi kecenderungan peningkatan persentase keluhan kesehatan bagi penduduk yang punya kebiasaan merokok yang dilakukan setiap hari sebelum satu bulan terakhir (periode pencacahan SUSENAS), serta terdapat sejumlah perokok aktif yang merokok setiap hari dari kalangan penduduk yang berstatus mengurus rumah tangga.

Kata kunci: kebiasaan merokok, mortalitas, susenas.

\section{PENDAHULUAN}

Mortalitas dan morbiditas merupakan dua hal yang saling berkaitan. Biasanya jika angka kematian meningkat maka morbiditas juga meningkat. Mortalitas disebut juga sebagai kematian. Morbiditas dapat berupa kesakitan fisik akibat penyakit tertentu seperti kanker, tumor, infeksi, dan lain-lain. Morbiditas bahkan dapat berupa trauma psikologis (Lubis, 2016).

Menurut Lestari (2019), Angka Kematian Kasar atau Crude Death Rate (CDR) dapat digunakan sebagai salah satu parameter mortalitas. Angka Kematian Kasar sangat 
dipengaruhi oleh struktur umur penduduk. Ada kecenderungan bahwa semakin banyak penduduk lansia di suatu wilayah atau negara maka Angka Kematian Kasar akan ikut meningkat. Proses aging di suatu wilayah menjadi tanda bahwa angka kematian sudah menurun sebab angka harapan hidup terus meningkat. Meski angka kematian turun namun tidak berarti tingkat morbiditas ikut turun. Bisa saja terjadi sebaliknya yaitu tingkat morbiditas tetap atau justru meningkat meskipun mortalitas turun.

Diantara faktor penyebab terjadinya banyak kasus kematian adalah karena kebiasaan (perilaku). Perilaku adalah satu diantara empat faktor yang mempengaruhi derajat kesehatan menurut Hendrik Blum (1974). Tiga faktor lainnya adalah lingkungan, pelayanan kesehatan, dan genetik. Lingkungan merupakan faktor terbesar yang paling berpengaruh terhadap derajat kesehatan seseorang.

Ada perbedaan antara faktor penyebab kematian pada setiap kelompok umur. Kematian pada kelompok umur lansia lebih banyak disebabkan oleh penyakit yang bersifat menahun seperti stroke, hipertensi, diabetes, jantung, dan lain-lain. Sementara itu untuk kematian pada kelompok umur tengah (usia produktif) cenderung disebabkan oleh penyakit yang berasal dari perilaku (gaya hidup). Kelompok umur tengah memiliki kerentanan terhadap rokok, minuman beralkohol, narkoba, dan gaya hidup yang tidak sehat. Diantara faktor tersebut, salah satu yang paling besar di Indonesia adalah rokok. Indonesia adalah salah satu negara dengan tingkat konsumsi rokok cukup tinggi didunia (Parmastuty, 2016).

Tahun 2015 sekitar 1,1 milyar penduduk dunia merokok dengan proporsi laki-laki yang merokok lebih banyak dibanding perempuan (Worldbank, 2019). Meskipun secara persentase jumlah penduduk yang merokok turun namun dari angka absolut terjadi peningkatan terutama di Afrika. Banyak penelitian yang membuktikan bahwa merokok dapat menyebabkan resiko kematian. Merokok memperbesar peluang terserang penyakit - penyakit berat yang membawa resiko kematian.

Berdasarkan Gambar 1 di bawah ini terlihat bahwa ada kenaikan yang cukup besar jumlah perokok laki-laki di Indonesia. Tren yang selalu meningkat dari tahun 2010 hingga 2016. Bahkan tahun 2005 jumlah perokok di Indonesia sudah mencapai $65 \%$ dari total jumlah laki-laki dan tahun 2016 sudah mencapai lebih dari $75 \%$. Ini artinya sekitar $3 / 4$ penduduk laki-laki dewasa di Indonesia adalah perokok aktif.

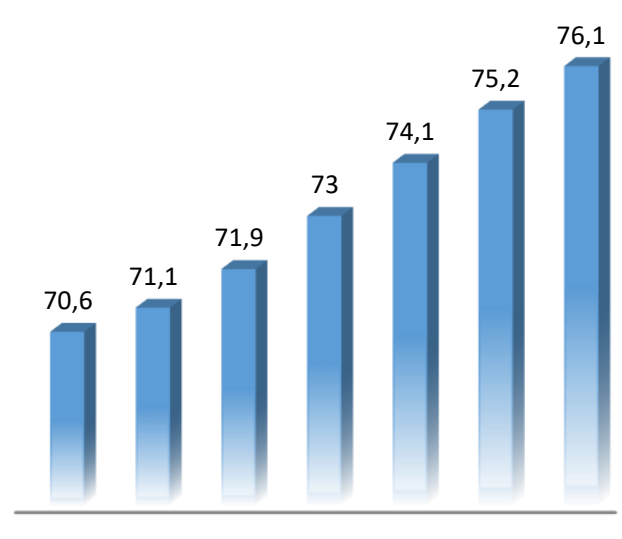

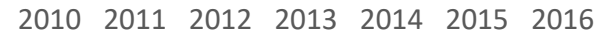

Gambar 1. Persentase Laki-Laki Merokok di Indonesia

Sumber: Worldbank, 2019

Seiring dengan bertambahnya jumlah perokok di Indonesia, ternyata jumlah kasus penderita penyakit paru-paru akibat rokok juga ikut meningkat. Hal ini tentu tidak terlalu mengagetkan mengingat tingginya konsumsi rokok perkapita di Indonesia. Bahkan ada kecederungan bahwa perokok mayoritas berasal dari keluarga dengan kelas ekonomi menengah ke bawah. Tentu ini 
sangat merugikan. Wardani dkk (2015) menyatakan ada peningkatan pasien di Inggris yang terdiagnosis kanker paru-paru dan gangguan saluran pernapasan akibat rokok. Hal ini terus meningkat seiring pertambahan konsumen rokok akibat sifat kecanduan (addiction). Penelitian yang dilakukan oleh Thun dkk (2000) disebutkan bahwa 90\% kematian akibat kanker paru awalnya disebabkan oleh rokok. Laki-laki perokok beresiko terhadap kematian akibat kanker paru-paru 22,4 lebih besar dibandingkan laki-laki non-perokok dan 11,9 kali lebih besar pada perempuan.

Ada kecenderungan penderita kanker paru-paru semakin bertambah seiring bertambah banyaknya jumlah perokok. Data yang disajikan dalam beberapa jurnal dan artikel terkait perokok hanya sebatas orang dewasa. Di beberapa negara berkembang dan miskin sudah jamak dijumpai perokok yang berusia muda (remaja) dan bahkan pernah dijumpai di Indonesia ada balita yang merokok. Hepilita dkk (2020) menyatakan bahwa kematian akibat kebiasaan merokok tidak terikat dengan faktor umur. Umur individu merupakan faktor internal penyebab kematian sedangkan kebiasaan merokok termasuk faktor eksternal atau faktor dari luar individu.

Dari paparan sebelumnya diketahui bahwa merokok merupakan kebiasaan yang dapat merusak kesehatan dan sudah dibuktikan oleh berbagai penelitian mengenai hubungannya dengan berbagai macam penyakit yang dapat berakibat kepada terjadinya morbiditas maupun mortalitas. Oleh karena itu penelitian ini bertujuan untuk melihat bagaimana gambaran Angka Kematian Kasar (CDR) di Indonesia serta gambaran penduduk yang merokok di Indonesia menurut jenis kelamin, kegiatan seminggu terakhir, keluhan kesehatan dan kebiasaan merokok satu bulan terakhir dan sebelum satu bulan terakhir.

\section{METODE PENELITIAN}

Penelitian ini menggunakan analisis deskriptif. Sumber data yang digunakan adalah raw data Survei Sosial Ekonomi Nasional (SUSENAS) Indonesia bulan Maret tahun 2019. Dari data SUSENAS tersebut akan diketahui gambaran penduduk yang merokok menurut jenis kelamin, kegiatan seminggu terakhir, keluhan kesehatan dan kebiasaan merokok satu bulan terakhir dan sebelum satu bulan terakhir dalam periode pencacahan.

Raw data SUSENAS tersebut diolah menggunakan SPSS versi 21 dengan memberikan penimbang atau bobot agar hasilnya dapat digunakan untuk generate sampai level Indonesia. Raw data dari masing-masing variabel yang masih berupa pengkodean tertentu sesuai kuesioner penelitian ketika dilakukan pengolahan pada SPSS diberikan label sesuai dengan pengkategorian yang diinginkan agar ketika dilakukan analisis mampu dengan mudah dipahami. Hasil olah data kemudian disajikan dalam bentuk tabel persentase menggunakan tabel silang (cross tabulation).

\section{HASIL DAN PEMBAHASAN}

Pada hakikatnya hampir semua orang menginginkan umur yang panjang, tetapi akan lebih banyak penyakit yang mengancam seseorang selama proses kehidupan panjangnya. Gambar 2 menunjukkan adanya penurunan jumlah Angka Kematian Kasar (CDR) di Indonesia dan rata-rata Dunia. Secara umum Indonesia dan Dunia memiliki level CDR yang hampir sama pada tahun 1960. Kemudian rata-rata CDR Dunia turun secara cepat sedangkan Indonesia turun secara lambat. Periode 
1975-1978 tren penurunan CDR Indonesia kembali bertemu di level yang sama dengan rata-rata CDR Dunia. Kemudian tahun mulai 1980 penurunan CDR Indonesia lebih cepat dibandingkan Dunia. Tren ini terus berlanjut hingga tahun 2016 sehingga posisi CDR Indonesia sudah dibawah rata-rata CDR Dunia.

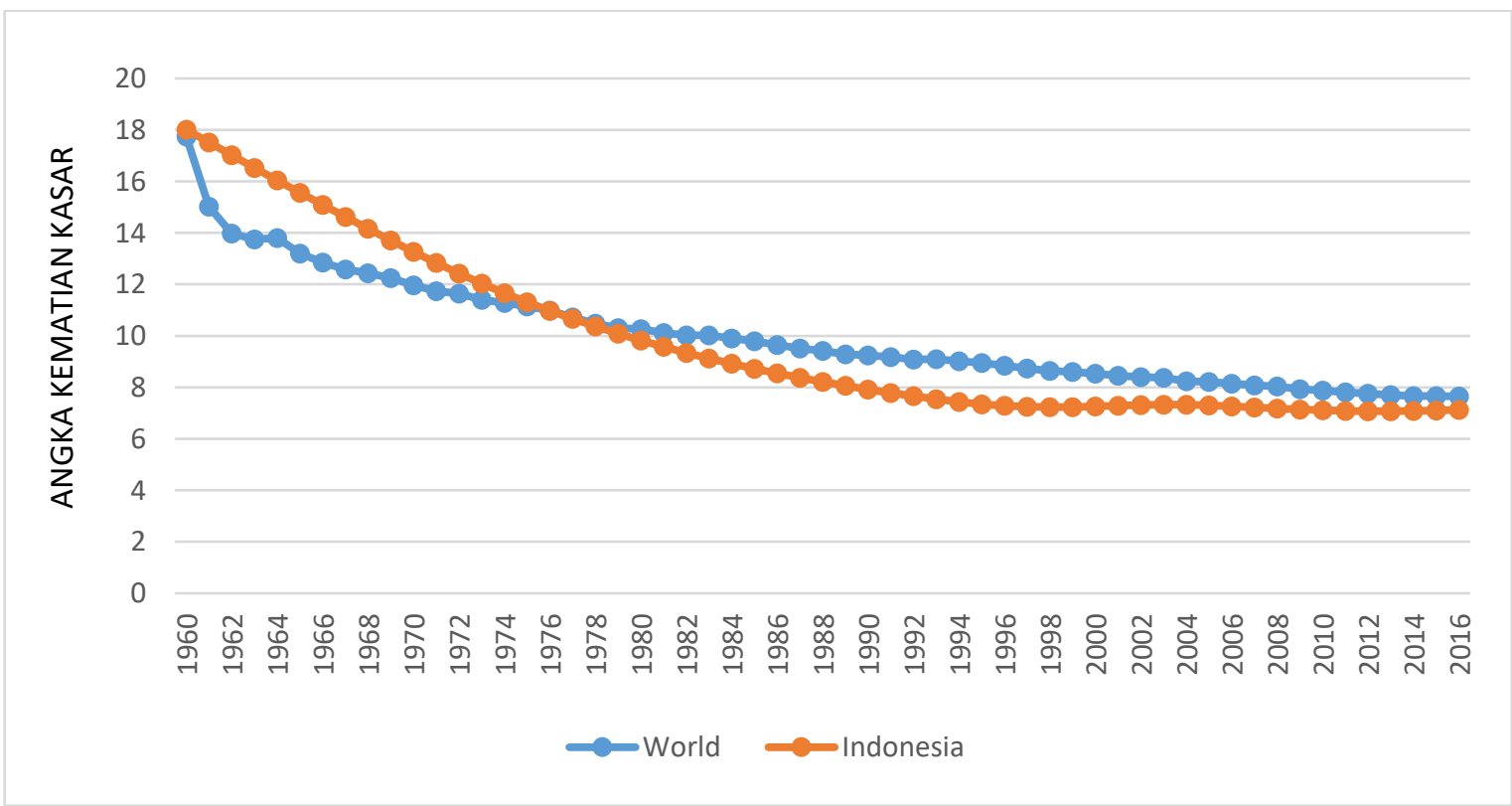

Gambar 2. Angka Kematian Kasar Indonesia dan Dunia

Sumber : Worldbank, 2019

Ada fenomena menarik terkait penurunan CDR Indonesia. Angka Kematian Kasar Indonesia sebenarnya mengalami fluktuasi. Angka Kematian kasar (CDR) Indonesia sempat mengalami kenaikan pada periode 1994 - 1999 kemudian mulai naik kembali periode 2000 hingga 2003. Periode 2004 2016 kembali turun secara perlahan. Secara umum CDR Dunia juga mengalami fluktuasi dan kecenderungan yang terus turun tidak sebesar Indonesia sehingga CDR Indonesia berada di bawah level Dunia.

Penurunan atau peningkatan CDR di sutau negara dapat dipengaruhi oleh penurunan atau peningkatan faktor resiko infeksi dan serangan penyakit kronis pada suatu kohor. Kanker paru-paru merupakan salah satu infeksi yang paling banyak menyebabkan kematian bagi laki-laki dewasa di Indonesia. Sebanyak 21,8\% pasien kanker di Indonesia adalah pengidap kanker paru-paru. Salah satu faktor resiko terbesar yang menyebabkan kanker paruparu adalah karena kebiasaan merokok (Prasetio dkk, 2019). Selain itu penelitian lain yang dilakukan oleh Lipfert (2019) membuktikan bahwa rokok merupakan pemicu paling besar terhadap kanker paruparu dimana ada kecenderungan bahwa orang-orang yang aktif merokok beresiko lebih tinggi terkena kanker paru-paru. Sekitar $85 \%$ - 90\% penderita kanker paruparu disebabkan oleh kebiasaan merokok aktif. 
Tabel 1.

Persentase Kebiasaan Merokok Tembakau Menurut Jenis Kelamin

\begin{tabular}{lcccc}
\hline \multirow{2}{*}{ Jenis Kelamin } & \multicolumn{4}{c}{ Kebiasaan Merokok Tembakau } \\
\cline { 2 - 5 } & Setiap Hari & $\begin{array}{c}\text { Tidak } \\
\text { Setiap Hari }\end{array}$ & $\begin{array}{c}\text { Tidak } \\
\text { Merokok }\end{array}$ & $\begin{array}{c}\text { Tidak } \\
\text { tahu }\end{array}$ \\
\hline Laki-laki & 97,7 & 95,0 & 36,3 & 41,5 \\
Perempuan & 2,3 & 5,0 & 63,7 & 58,5 \\
\hline
\end{tabular}

Sumber : Survei Sosial Ekonomi Nasional 2019, Diolah.

Berdasarkan hasil Susenas tahun 2019 diketahui bahwa ada $97,7 \%$ laki-laki dan 2,3\% perempuan yang aktif merokok setiap hari. Mayoritas kebiasaan merokok dilakukan oleh laki-laki dan hanya sebagian kecil perempuan yang merokok karena kebiasaan merokok bagi perempuan masih dianggap tabu bagi masyarakat Indonesia (Tabel 1). Kebiasaan merokok dapat memperbesar resiko terkena kanker paru atau gangguan kardiovaskuler serta konsekuensi kesehatan negatif lainnya dan dapat menyebabkan kondisi kesehatan yang lebih buruk pada wanita terutama pada kondisi-kondisi khusus seperti wanita menopouse dan wanita hamil (Sari dkk, 2019).

Tabel 2.

Persentase Kebiasaan Merokok Tembakau Menurut Keluhan Kesehatan yang Dialami

\begin{tabular}{ccccc}
\hline \multirow{2}{*}{ Keluhan Kesehatan } & \multicolumn{4}{c}{ Kebiasaan Merokok Tembakau } \\
\cline { 2 - 5 } & Setiap Hari & $\begin{array}{c}\text { Tidak } \\
\text { Setiap Hari }\end{array}$ & $\begin{array}{c}\text { Tidak } \\
\text { Merokok }\end{array}$ & Tidak tahu \\
\hline Ya & 25,5 & 27,9 & 27,0 & 19,5 \\
Tidak & 74,5 & 72,1 & 73,0 & 80,5 \\
\hline
\end{tabular}

Sumber : Survei Sosial Ekonomi Nasional 2019, Diolah.

Tabel 2 menunjukkan bahwa ada 25,5\% perokok aktif yang merokok setiap hari telah mengalami keluhan kesehatan sedangkan $74,5 \%$ perokok yang merokok setiap hari ternyata justru tidak mengalami keluhan kesehatan. Hal ini disebabkan sifat destruktif rokok tidak berdampak pada jangka waktu pendek melainkan dalam jangka waktu yang panjang. Seseorang yang aktif merokok hari ini, bisa jadi baru akan mengalami keluhan sakit akibat rokok antara 15-20 tahun mendatang. Hal ini karena adanya timbunan racun dalam saluran pernapasan seorang perokok. Semakin sering dan banyak rokok yang dikonsumsi maka semakin besar resiko terkena kanker paru atau gangguan kardiovaskuler dan sebaliknya (Saminan, 2016). 
Tabel 3.

Persentase Kebiasaan Merokok Tembakau (Sebelum 1 Bulan Terakhir) Menurut Keluhan Kesehatan yang Dialami

\begin{tabular}{ccccc}
\hline \multirow{2}{*}{ Keluhan Kesehatan } & \multicolumn{4}{c}{$\begin{array}{c}\text { Kebiasaan Merokok Tembakau } \\
\text { (Sebelum 1 Bulan Terakhir) }\end{array}$} \\
\cline { 2 - 5 } & Setiap & $\begin{array}{c}\text { Tidak } \\
\text { Setiap Hari }\end{array}$ & $\begin{array}{c}\text { Tidak } \\
\text { Merokok }\end{array}$ & $\begin{array}{c}\text { Tidak } \\
\text { tahu }\end{array}$ \\
\hline Ya & 47,6 & 37,0 & 26,7 & 25,7 \\
Tidak & 52,4 & 63,0 & 73,3 & 74,3 \\
\hline
\end{tabular}

Sumber : Survei Sosial Ekonomi Nasional 2019, Diolah.

Jika dicermati lebih jauh, ternyata ada kecenderungan peningkatan persentase keluhan kesehatan bagi penduduk yang punya kebiasaan merokok yang dilakukan setiap hari sebelum satu bulan terakhir (dahulu) yaitu sebesar 47,6\%. Kemudian ada $37 \%$ penduduk yang mengalami keluhan kesehatan meski tidak merokok setiap hari (Tabel 3).

Karakteristik perokok di Indonesia menurut kegiatan seminggu terakhir masih didominasi oleh penduduk yang bekerja baik dengan persentase sebesar $92,1 \%$ yang aktif merokok tembakau setiap hari. Penduduk berstatus sekolah (pelajar) yang merokok aktif setiap hari sebesar $1,1 \%$. Perokok dari kalangan pelajar ini tentu menjadi keprihatinan bagi pemerintah sebab generasi muda yang sudah kecanduan rokok maka kondisi kesehatannya pasti menurun. Padahal semestinya para remaja tersebut dapat menjaga kesehatan agar tidak beresiko terkena penyakit akibat rokok.

Tabel 4.

Persentase Kebiasaan Merokok Tembakau Menurut Jenis Kegiatan Utama

\begin{tabular}{ccccc}
\hline \multirow{2}{*}{ Jenis Kegiatan } & \multicolumn{4}{c}{ Kebiasaan Merokok Tembakau } \\
\cline { 2 - 5 } & Setiap Hari & $\begin{array}{c}\text { Tidak } \\
\text { Setiap Hari }\end{array}$ & $\begin{array}{c}\text { Tidak } \\
\text { Merokok }\end{array}$ & Tidak tahu \\
\hline Bekerja & 92,1 & 83,4 & 39,3 & 32,5 \\
Sekolah & 1,1 & 4,6 & 27,6 & 34,8 \\
$\begin{array}{c}\text { Mengurus rumah tangga } \\
\text { Lainnya selain kegiatan } \\
\text { pribadi }\end{array}$ & 3,6 & 6,8 & 30,6 & 28,6 \\
\hline
\end{tabular}

Sumber : Survei Sosial Ekonomi Nasional 2019, Diolah.

Terdapat $3,6 \%$ perokok aktif yang merokok setiap hari dari kalangan penduduk berstatus mengurus rumah tangga (Tabel 4). Jika diasumsikan bahwa yang berstatus mengurus rumah tangga ini adalah para ibu rumah tangga, maka ini cukup mengejutkan.
Kemudian muncul pertanyaan: apa alasan mereka merokok? Adakah kaitannya dengan tingkat stress? Atau faktor lingkungan yang sudah jamak merokok bagi ibu rumah tangga? Perlu dilakukan kajian lebih dalam untuk menjawab pertanyaan tersebut. 
Analisis akan menarik jika ada data tentang karakteristik penderita kanker paru dan kebiasaan merokok di masa lalu. Kemudian apakah ada perbedaan karakteristik antara penderita kanker paruparu menurut jenis kelamin, kegiatan seminggu terakhir, kebiasaan merokok satu bulan terakhir dan sebelum satu bulan terakhir. Karakteristik ini dipilih berdasarkan penelitian Janssen dkk (2012) yang menemukan bahwa kematian menurut wilayah di Belanda sebagian besar disebabkan oleh kebiasaan merokok. Selain itu jumlah laki-laki yang meninggal karena rokok jauh lebih tinggi dibandingkan perempuan sebab memang jumlah perokok aktif mayoritas laki-laki. Menurut Pampel (2005) resiko kematian akibat rokok tidak berhubungan dengan kesetaraan gender namun lebih berkaitan dengan pola sebaran rokok. Ada kecenderungan peningkatan jumlah perokok perempuan disaat terjadi tren perokok laki-laki sudah mencapai titik puncak. Sementara itu disisi lain terjadi penurunan tren kematian laki-laki akibat rokok.

Penelitian Pampel (2005) menunjukkan bahwa kematian penduduk pada usia 70 tahun keatas lebih banyak diakibatkan oleh faktor selain rokok. Kecil kemungkinan kematian penduduk diatas 70 tahun yang secara spesifik akibat rokok. Fakta yang mengejutkan justru ada resiko penurunan angka harapan hidup bagi penduduk usia 3569 tahun akibat kebiasaan merokok. Di negara dengan pendapatan perkapita tinggi, terjadi peningkatan prevalensi merokok secara signifikan sehingga kejadian kematian akibat rokok dimasa depan dapat diprediksi sejak saat ini.

\section{SIMPULAN}

Merokok merupakan kebiasaan yang dapat merusak kesehatan dan dapat menyebabkan berbagai macam penyakit yang dapat berakibat kepada terjadinya morbiditas maupun mortalitas dimana Angka Kematian Kasar (CDR) dapat digunakan sebagai salah satu parameter mortalitas. Mulai tahun 1980-2016 penurunan CDR Indonesia lebih cepat dibandingkan Dunia. Penurunan dan peningkatan angka CDR dipengaruhi oleh faktor resiko infeksi salah satunya kanker paru-paru, dimana kanker paru-paru merupakan penyakit yang dapat muncul karena kebiasaan merokok.

Berdasarkan hasil Susenas tahun 2019 diketahui bahwa mayoritas kebiasaan merokok dilakukan oleh laki-laki dan hanya sebagian kecil perempuan, hanya sebagian kecil saja dari perokok aktif yang mengalami keluhan kesehatan namun terjadi kecenderungan peningkatan persentase keluhan kesehatan bagi penduduk yang punya kebiasaan merokok yang dilakukan setiap hari sebelum satu bulan terakhir (periode pencacahan SUSENAS), serta terdapat sejumlah perokok aktif yang merokok setiap hari dari kalangan penduduk yang berstatus mengurus rumah tangga.

\section{DAFTAR PUSTAKA}

Blum, H. L. B. H. (1974). Faktor yang mempengaruhi status derajat kesehatan masyarakat atau perorangan. Ministry Health of Indonesia.

Hepilita, Y., \& Mariati, L. H. (2020). Deteksi Dini Tingkat Tekanan Darah Pada Perokok Usia Muda. Jurnal Ilmu Kesehatan Vol, 9(1). 
Janssen, F., \& Spriensma, A. (2012). The contribution of smoking to regional mortality differences in the Netherlands. Demographic Research, 27, 233-260. http://www.jstor.org/stable/26349923

Lestari, D. (2019). Comparison Of Indonesian Population Growth By Province 1995-2015 Based On Supas Data. JCIC: Jurnal CIC Lembaga Riset dan Konsultan Sosial, 1(1), 37-48.

Lipfert, F. W., \& Wyzga, R. E. (2019). Longitudinal relationships between lung cancer mortality rates, smoking, and ambient air quality: a comprehensive review and analysis. Critical reviews in toxicology, 49(9), 790-818.

Lubis, N. L. (2016). Psikologi Kespro. Wanita dan Perkembangan Reproduksinya: Ditinjau dari Aspek Fisik dan Psikologinya. Kencana: Jakarta.

Pampel, F. (2005). Forecasting sex differences in mortality in high income nations: The contribution of smoking. Demographic Research, 13, 455-484. Retrieved from http://www.jstor.org/stable/26347873

Parmastuty, O. (2016). Estimasi Angka Kematian dan Years of Life Lost (YLL) Penyakit Kanker Akibat Rokok di Indonesia (Doctoral dissertation, Universitas Gadjah Mada).

Prasetio, R. T., \& Susanti, S. (2019). Prediksi Harapan Hidup Pasien Kanker Paru Pasca Operasi Bedah Toraks Menggunakan Boosted k-Nearest Neighbor. JURNAL RESPONSIF: Riset Sains \& Informatika, 1(1), 64-69.

Saminan. (2016). Efek Perilaku Merokok Terhadap Saluran Pernapasan. Jurnal Kedokteran Syiah Kuala Volume 16 No 3 Desember 2016 : 191-194.

Sari, A. N., \& Istighosah, N. (2019). Hubungan Olahraga, Kopi dan Merokok dengan Kualitas Hidup Wanita Menopause yang Tinggal Di Wilayah Pedesaan. Jurnal Ners dan Kebidanan (Journal of Ners and Midwifery), 6(3), 326-332.

Thun, M. J., Apicella, L., \& Henley, S.J. (2000) "Smoking vs. Other Risk Factors as the Cause of Smoking-Attributable Deaths: Confounding in the Courtroom." JAMA 284:706-712.

Wardani, N. K., Winarsih, S., \& Sukini, T. (2015). Hubungan Antara Paparan Asap Rokok Dengan Kejadian Infeksi Saluran Pernapasan Akut (ISPA) Pada Balita Di Desa Pucung Rejo Kabupaten Magelang, Tahun 2014. Jurnal Kebidanan, 4(8), 18-25.

Worldbank. (2019). Prevalence of current tobacco use, males (\% of male adults). New Hampshire: United States. Retrieved https://data.worldbank.org/indicator/SH.PRV.SMOK.MA. 